\title{
Cam Dekorasyonunda Alternatif Bir Malzeme Olarak Uçucu Kül Kullanımının Araştırılması
}

Yrd. Doç. Dr. Selvin Yeşilay

Arş. Gör. Ufuk Akbey

\section{Özet}

Cam, günümüzde olduğu gibi çok eski zamanlardan beri pratikte ve dekoratif amaçlı kullanılagelen amorf yapıll bir malzemedir. Geçmișten günümüze cam dekorasyonunda çeșitli araçlar ve teknikler kullanılmıștır. Farklı özelliklere sahip özgün dekor etkileri elde etmek için uçucu kül, odun külü, metalik tuzlar vb. birçok malzeme cam yüzeyinde dekor amaçlı kullanılabilir. Uçucu kül, pulverize kömürün yanması sonucu oluşan ve gazlarla yanma odasından taşınan kalıntıdır. Tüm dünyada yüksek miktarda uçucu kül üretilmektedir ve atıkların aktarılması yüksek maliyetli bir sorun olagelmiștir. Uygun bir șekilde işlem görmeyen atıklar önemli çevresel sorunlara neden olduğundan, atıkların elden çıkarılması için uçucu küllerin tarım, sanat ve sanayi gibi alanlarda potansiyel olarak yeniden kullanılması arastrurlmaktadir. Bu calısmada farklı ve yeni görsel etkiler ve dokular elde etmek isin cam yüzeylerinde usucu kül kullanlarak dekoratif camlar üretilmistir. Cam sanatşları için ilgins bir dekorasyon yöntemi kesfetmenin yanı sıra aynı zamanda sevreye ve sağı̆̆g zararlı atık bir maddenin etkisini azaltmaya katkıdo bulunmayı da amaçlanmıştır.

Anahtar Kelimeler: Cam, Cam Dekorasyonu, Uçucu Kül, Geri Dönüşüm, Cam Sanatı

INVESTIGATION OF FLY ASH AS AN ALTERNATIVE MATERIAL IN GLASS DECORATION

\section{Abstract}

Glass is an amorphous material that has been used for practical and decorative purposes since ancient times as it is today. In the past, various tools and techniques have been used in glass decoration. Many materials can be used for decorating on the glass surface as fly ash, wood ash, metallic salts, etc. to achieve original decor effects with different properties. Fly ash is a residue formed by the burning of the pulverized coal and carried from the combustion chamber by the gases. High quantities of fly ash are being produced all over the world and the transfer of waste has become a costly problem. Potentially reuse of fly ash in areas such as arriculture, art and industry is being investigated in order to remove untreated wastes which causes significant environmental and industy is be hroble problems. his bis study decoras In addition to discover an also aimed at contributing to reducing the influence of a material which is harmful to the environment and health.

Keywords: Glass, Glass Decoration, Fly Ash, Recycling, Glass Art

Yrd. Doç. Dr. Selvin Yeşilay, Anadolu Üniversitesi, Güzel Sanatlar Fakültesi, Cam Bölümü , Eskişsehir E-posta: selvin.yesilay@gmail.com

Arş. Gör. Ufuk Akbey, Anadolu Üniversitesi, Güzel Sanatlar Fakültesi, Cam Bölümü , Eskişehir

E-posta: urakbey@anadolu.edu.tr 


\section{Giriş}

Çağlar boyunca doğallık, saflık ve aydınlanmanın sembolü olan cam, yenilik, basitlik, denge, hafiflik, durgunluk, sadelik ve görkemlilik kavramlarıla ön plana çıkmıştır [Yeşilay, 2008: 111].

Cam, insanoğlunun yaşamsal faaliyet alanlarıyla sınırlı kalmamış, aynı zamanda önemli bir sanat malzemesi haline gelmiştir. Üretimi sırasında sayısız farklılıkta özellikler sunması nedeniyle sınırsız ifade olanakları elde edilir. Cama kolayca tanınabilir ve kabul edilebilir bir yaklaşım getirmek için araştırma yapmak ve yöntem, malzeme, stil, içerik ve özgün bir yorumlama yöntemi içeren uyumlu bir ilişkiye sahip olmak gerekir [Cummings, 2009: 17].

Camın tipik sıcaklıklarda belirli bir sertliğe ve katılığa sahip olmak, yüksek sıcaklıklarda çalışılabiliyor olmak, hava koşullarına ve hidroflorik (HF) asit dışındaki çoğu kimyasala dayanıklı olmak gibi karakteristik özellikleri vardır. Cam hem günlük hayatta fayda sağlamak hem de dekoratif amaçlar için kullanılmıştır ve çeşitli şekillerde renklendirilmiş veya dekorlanmış olarak üretilmiştir. Üfleme cam kaplar sıkıştırma, basma, çekme, boyama, çizgi çekme (cam iplikler) ve yeniden şişirmeden önce renkli cam parçaları sarma (sıçrama etkisi oluşturmak için) gibi çeşitli teknikler kullanılarak süslenmiştir.

Günümüzde olduğu gibi antik dönemde de camın pratik ve dekoratif kullanımları olmuştur. Antik Yunanlılar, Romalılar ve Etruryalılar cam kapları mürekkep, gıda, kozmetik ve parfüm yağı depolamada kullanıyorlardı. Ayrıca camdan yapılmış sofra eşyaları, cam aynalar, cam lambalar ve cam pencereler hayatlarında oldukça büyük bir yer teşkil ediyordu. Zenginler evlerinde cam mozaikler, kakmalar ve heykeller kullanıyorlardı.

Günümüzün dinamik, modern ve otantik yaratıcılığının sonucu olarak oluşan cam sanatı çeşitli dekorasyon tekniklerinin gelişmesiyle canlanmaya başlamıştır. Dekorasyon işlemi, cam üretiminin temel safhasındaki ikinci uygulama esnasında cam sıcakken veya soğuyunca yapılır (Yeşilay, 2008: 112).

Cama uygulanan dekorasyon yöntemleri çok çeşitlidir ve güzel ve özgün etkiler elde etmek mümkündür. Günümüze kadar kullanılan temel cam dekorasyon teknikleri kumlama, kesme, boyama, aşındırma, metal kaplama ve dijital baskıdır (Cornett, 2004: 127, Capp, 1984: 64, Norman, 2012:208, Neal, 2002: 128, Sinclaire, 1997:350, Petrie, 2006: 128). Birçok malzeme,

https://www.khanacademy.org/partner-content/gettymuseum/antiquities/ancient-glassmaking/a/glassmaking-history-and-techniques yüksek sıcaklık dayanımlarında ve cam ile uyumlarında sorun yoksa cam dekorasyonunda kullanılabilir (Beveridge, 2005: 160).

Son yıllarda görülen endüstriyel ve ekonomik büyüme, ulusal ve uluslararası düzeyde kabul edilen atık yönetimi politikalarına rağmen, farklı atık türlerinin (kent, sanayi, inşaat vb.) üretiminde bir artışa neden olmuştur (Sorvari, 2014: 240).

Endüstriyel işlemler sonucunda, metalürji cürufu, enerji üretiminden gelen kül, madencilikten kaynaklanan atıklar, orman endüstrisindeki cevherler ve fiber çamurunun zenginleştirilmesinden gelen atıklar gibi çeşitli mineral artıkları meydana gelmektedir. Oluşan bu atıklar yeniden kullanım, geri dönüşüm veya yeni malzemelerin üretiminde kullanılma potansiyeline sahiptir.

Çeşitli üretim sektörlerinden atıkların atılması ve/veya yetersiz yönetimi, çevre üzerinde belirgin bir etkiye sahiptir. Bu atıklar su, toprak, hava ve gürültü kirliliğine neden olurken diğer komplikasyonlar arasında mevcut çevre sorunlarına yenilerinin eklenmesine de neden olurlar. Atıklar doğru bir şekilde yönetilirse, hammaddelerin tasarrufuna, doğal kaynakların ve iklimin korunmasına katkıda bulunan bir kaynağa dönüştürülebilir ve sürdürülebilir kalkınmayı teşvik ederler (Amin vd., 2016: 2681).

Bazı atıklar seramiklerde kullanılan hammaddelerle karşılaştırıldıklarında aynı kompozisyona sahiptirler ve bunlar sadece uyumlu değil üretim anlamında birçok fayda da getirebilirler (Junkes vd., 2011: 37).

Kömür uçucu külü; uçucu kül, toz haline getirilmiş uçucu kül ve kömür yakma ürünü gibi çeşitli isimlerle bilinir (Sear, 2001: 261). Kömür yakma işlemi sonucunda kömür külü oluşur ve \% 80'i çok ince olduğu için uçucu kül olarak adlandırılır. Kömürle çalışan termik santrallerden gelen katı atık olan uçucu kül, çevreciler için ciddi bir endişe haline gelmiştir (Sharma, 2013: 100).

Günümüzde uçucu kül, kullanıldığı birçok uygulamada arzu edilen belirli özelliklere sahip değerli bir malzeme olarak kabul edilmektedir.

Uçucu kül bileşiminde silisyum ve alümina içeren, renk ve doku etkisi açısından fark yaratabilecek cam yüzey dekorasyonu için umut verici bir malzemedir. Yanan kömürün kaynağına ve yapısına bağlı olarak, uçucu küllerin bileşenleri önemli derecede değişir, ancak tüm uçucu küller önemli miktarda silisyum dioksit (SiO2) (hem amorf ve kristalin), alüminyum oksit (Al203) ve kalsiyum oksit (CaO) içerirler. Yapısında başlıca elementler olarak azalan sırada $\mathrm{Si}, \mathrm{Al}, \mathrm{Fe}, \mathrm{Ca}, \mathrm{C}, \mathrm{Mg}, \mathrm{K}, \mathrm{Na}, \mathrm{S}, \mathrm{Ti}, \mathrm{P}$ ve $\mathrm{Mn}$ bulunmaktadır 
(Openshaw, 1992: 14, Littlea, 2008: 1329).

Bu çalışmada, sıcak cam üretiminde cam yüzeyinde farklı ve yeni bir dekor etkisi elde etmek için kömür uçucu külleri (Şekil 1) kullanılmıştır. İlk aşamada uçucu küllerin karakterizasyon testleri yapılmıştır. İkinci aşamada sıcak cam üfleme işlemi esnasında cam yüzeyine uçucu kül uygulanmıştır. Bu amaçla uçucu küller fırından alınan fıskanın üzerine sarılmıştır. Bir süre tromelde bekletildikten sonra ikinci katman sarılarak uçucu küllerin cam katmanlar arasında kalması sağlanmıştır. Uçucu küllerin tek başlarına ve farklı oranlarda cam boyası ve cam tozlarıyla karıştırılarak kullanılması sonucunda cam yüzeyinde çeşitli görsel etkiler elde edilmiştir.

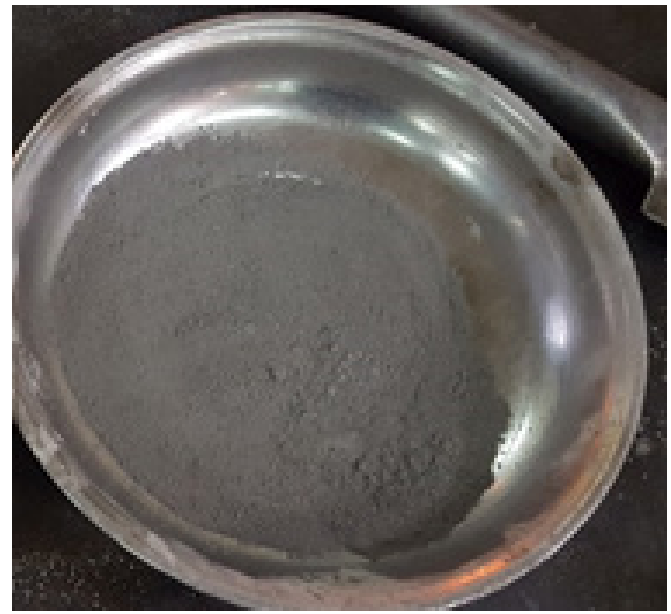

Şekil I. Çalışmada Kullanılan Uçucu Kül

\section{Deneysel Çalışmalar}

Çalışmada Çanakkale bölgesinde bulunan bir termik santralden temin edilen uçucu küller kullanılmıştır. Uygulamalar sıcak cam üretiminde dekor etkisi elde etmek amacıyla cam yüzeyinde yapıımıştır. Uçucu küller ilk olarak bilyeli değirmende 2 saat süreyle öğütülmüş ve iri taneleri uzaklaştırmak için $60 \mu \mathrm{m}$ elekten geçirilmiştir. Daha sonra kimyasal bileşimlerini belirlemek için uçucu küllerin XRF (X-Işınları florensası) analizi ve sıcaklığa bağlı davranışlarını belirlemek için ise TG-DTA (Termogravimetrik-Diferansiyel Termal analiz) analizleri yapılmıştır. Tüm çalışma boyunca uçucu küller sıcak cam yüzeyine 4 farklı sekilde uygulanmıştır. Birinci denemede kömür külleri beyaz boya ile oranları \% 50'şer olmak üzere tartılarak homojen bir șekilde karıştııımıștır. FA1 olarak kodlanan karısım fırından alınan cam fıska üzerine sarıldıktan sonra trommelde bekletilerek cam yüzeyi ile kül- boya karışımının bütünleşmesi sağlanmıştır. Daha sonra bir kat daha cam alınarak ikinci tabaka elde edilmiştir ve cama istenilen şekil verilmiştir (Şekil 2).

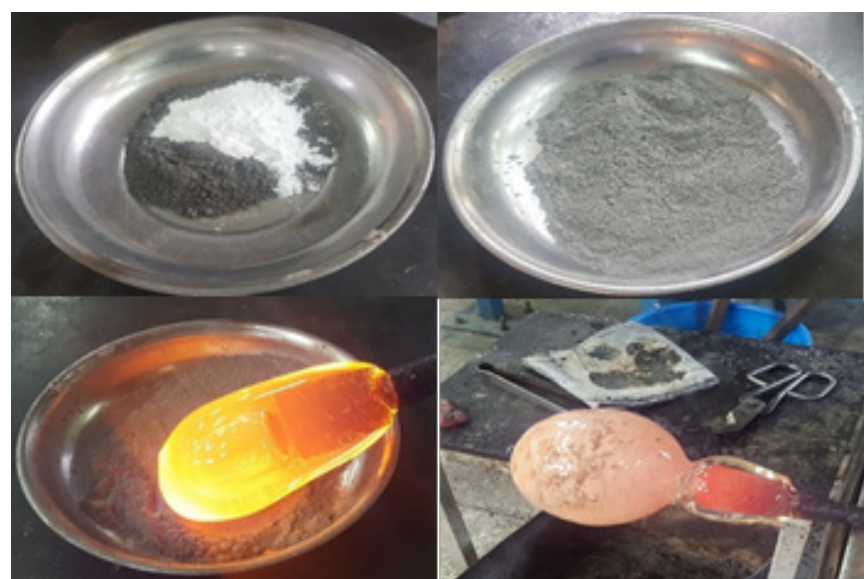

Şekil 2. FAI Kodlu Karışımla Yapılan Uygulamaya Ait Fotoğraflar

Uçucu küllerin bileşiminde oldukça yüksek miktarda Al2O3 (Alüminyum oksit) ve $\mathrm{SiO} 2$ (Silisyum dioksit) plastikliği az olan bileşenlerin bulunması sonucu cam yüzeyinde homojen bir şekilde dağılmamaktadır. Ayrıca şekillendirme sıcaklığında uçucu küller tam olarak yumuşamadıkları için cam yüzeyinde topaklanmalar oluşmaktadır. Bunu engellemek için sıcak cam fırınından alınan cam eriyiği soğuk suya dökülerek firitleştirilmiş ve fırında kurutulmuştur. Fırından alındıktan sonra bilyeli değirmende 4 saat süreyle öğütülmüş ve $60 \mu \mathrm{m}$ 'lik elekten geçirilmiştir. İkinci kademede kömür küllerinin sıcak cam yüzeyiyle olan etkileşimini arttırmak amacıyla hazırlanan bu cam tozları, ağırııça \% 10 oranında uçucu külle karıştırılarak bir karışım oluşturulmuştur (FA2). Bu karışıma \% 50 oranında kırmızı cam boyası ilave edilerek aynı yöntemle cam obje üretilmiştir (Şekil 3).

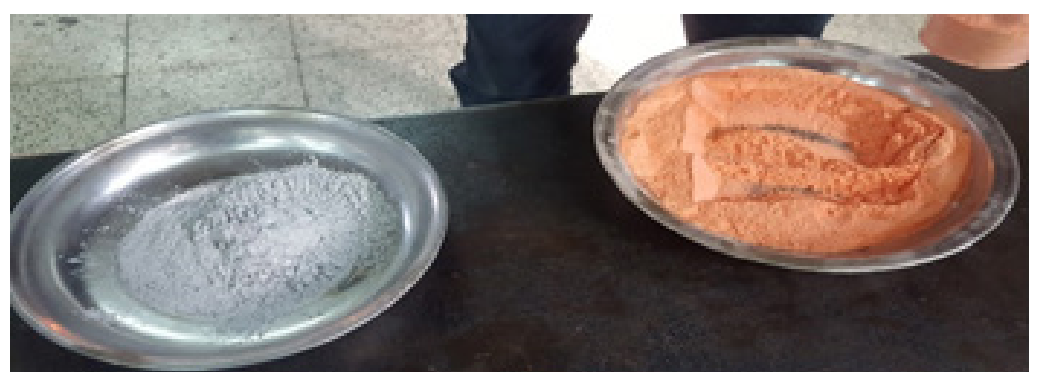

Şekil 3. FA2 Kodlu Karışımla Yapılan Uygulamaya Ait Fotoğraflar 


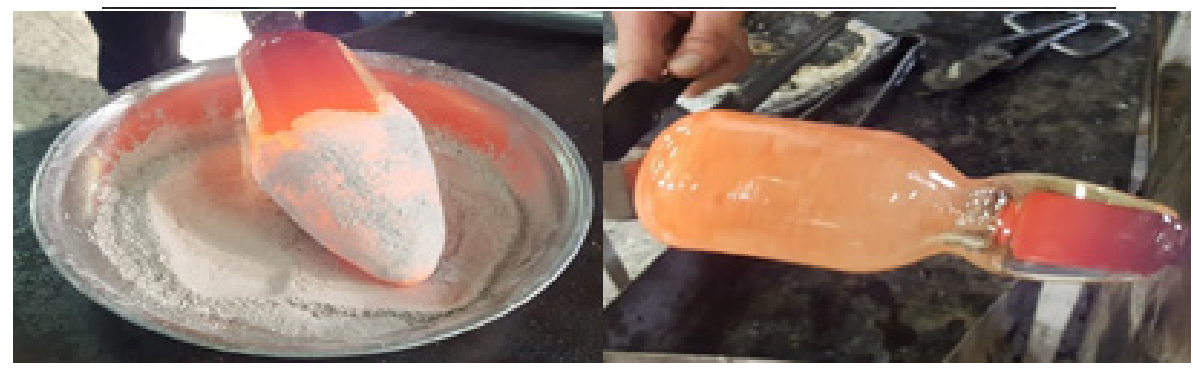

Şekil 3. FA2 Kodlu Karışımla Yapılan Uygulamaya Ait Fotoğraflar

Çalışmanın üçüncü aşamasında üretilen firitleştirilmiş cam tozu ağırlıkça \% 20 oranında uçucu kül ile karıştııımış (FA3) ve sıcak cam yüzeyine uygulanmıştır. Uçucu kül oranının artmasıyla cam yüzeyinde meydana gelen dekor ve doku etkisi incelenmiştir (Şekil 4).

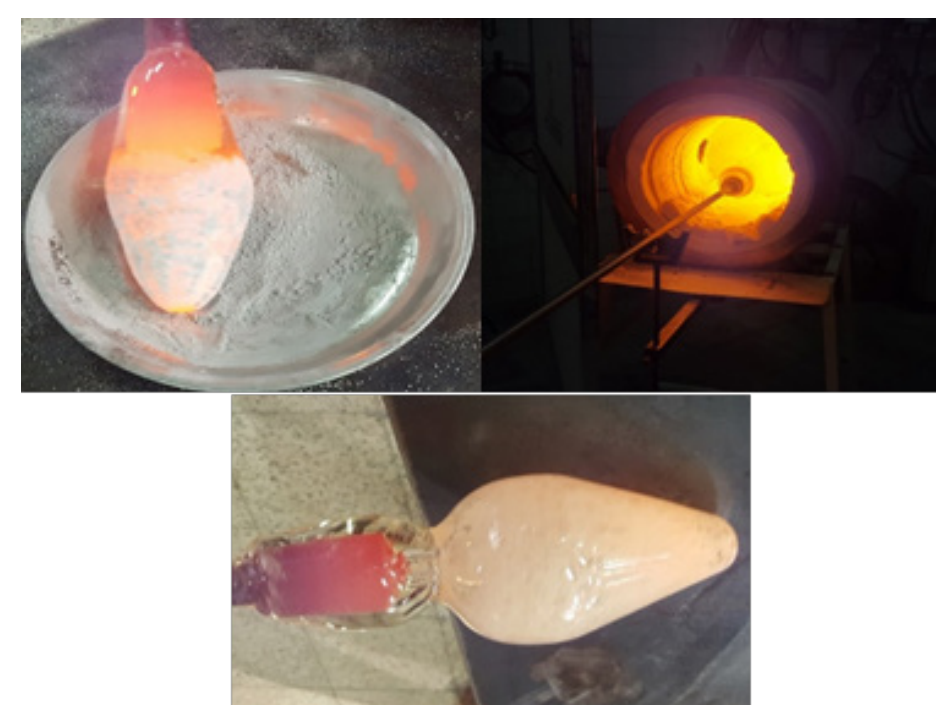

Şekil 4. FA3 Kodlu Karışımla Yapılan Uygulamaya Ait Fotoğraflar

Çalışmanın son aşamasında firitleştirilmiş cam tozuna ağırlıkça \% 50 oranında uçucu kül ilave edilerek homojen bir şekilde karıştırılmıştır (FA4). FA4 kodlu bu karısıım beyaz renkli sıcak cam üzerine uygulanarak etkileri incelenmisstir. Beyaz renkli cam elde etmek için iki farklı yöntem uygulanmıştır. Birinci yöntemde (FA4-a) fırından alınan eriyik haldeki şeffaf cam üzerine beyaz renkli cam tozu alınarak ve tromelde Isıtılarak yüzeyde beyaz renk elde edilmiştir. İkinci yöntemde (FA4-b) ise beyaz renk elde etmek için fırından alınan şeffaf cam üzerine beyaz renkli cam bar çubuk kaplanmıştır. Beyaz renkli bar çubuk kaplama ile toz ile yapılan çalışmaya göre daha homojen ve pürüzsüz bir kaplama elde edilmiştir. Toz renk ile elde edilen cam üzerine yapılan uçucu kül uygulaması Şekil 5 'te, bar çubuk ile elde edilen cam üzerine yapılan uçucu kül uygulaması ise Şekil $\sigma^{\prime} \mathrm{da}$ sunulmuştur.

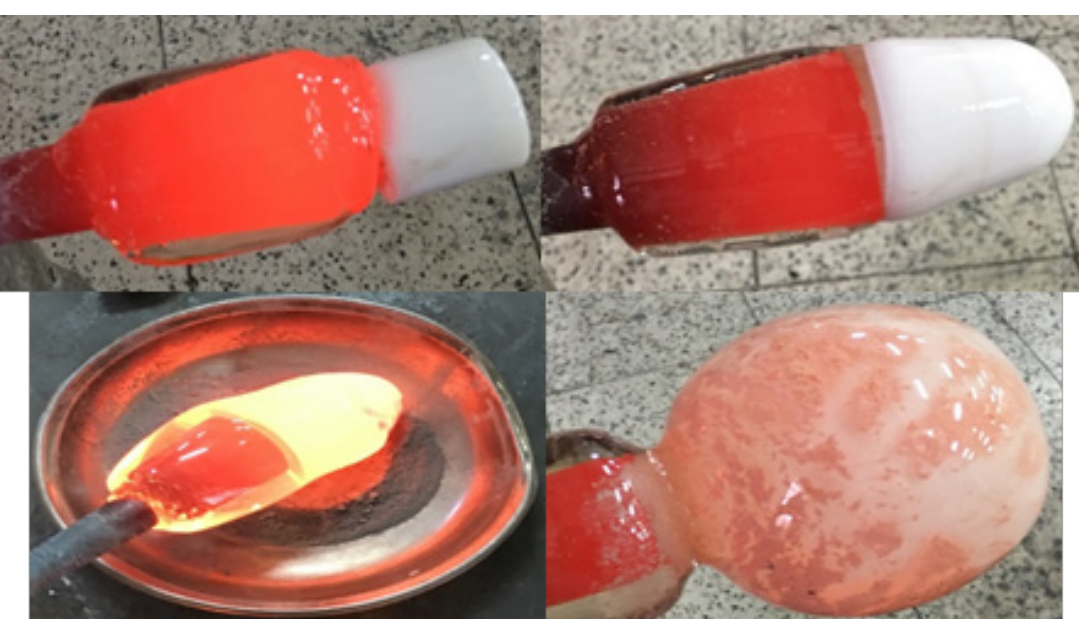

Şekil 6. FA4-B Kodlu Karışımla Yapılan Uygulamaya Ait Fotoğraflar

\section{Sonuçlar ve Tartışma}

Uçucu küllere ait kimyasal analiz sonuçları Tablo l'de sunulmuştur.

\begin{tabular}{|l|c|c|c|c|c|c|c|c|}
\hline Oksitler & $\mathrm{SiO}_{2}$ & $\mathrm{Al}_{2} \mathrm{O}_{3}$ & $\mathrm{Fe}_{2} \mathbf{O}_{3}$ & $\mathbf{C a O}$ & $\mathrm{MgO}$ & $\mathrm{K}_{2} \mathbf{O}$ & $\mathbf{T i O}_{2}$ & ${ }^{*}$ A.Z. \\
\hline Ağırlıça \% & 38.68 & 18.41 & 4.25 & 18.57 & 1.42 & 1.35 & 0.28 & 17.04 \\
\hline
\end{tabular}

Tablo I. Uçucu Küllere Ait Kimyasal Analiz Sonuçları (Ağırlıkça \%)

Tablo 1'de görülen kimyasal analiz sonuçlarına göre uçucu küllerin SiO2 ve $\mathrm{Al} 2 \mathrm{O} 3$ içeren refrakter fazları içerdiği açıktır.

Şekil 7'de uçucu küllere ait TG/DTA grafiği verilmiştir.

Ateș Zaiyatı. 


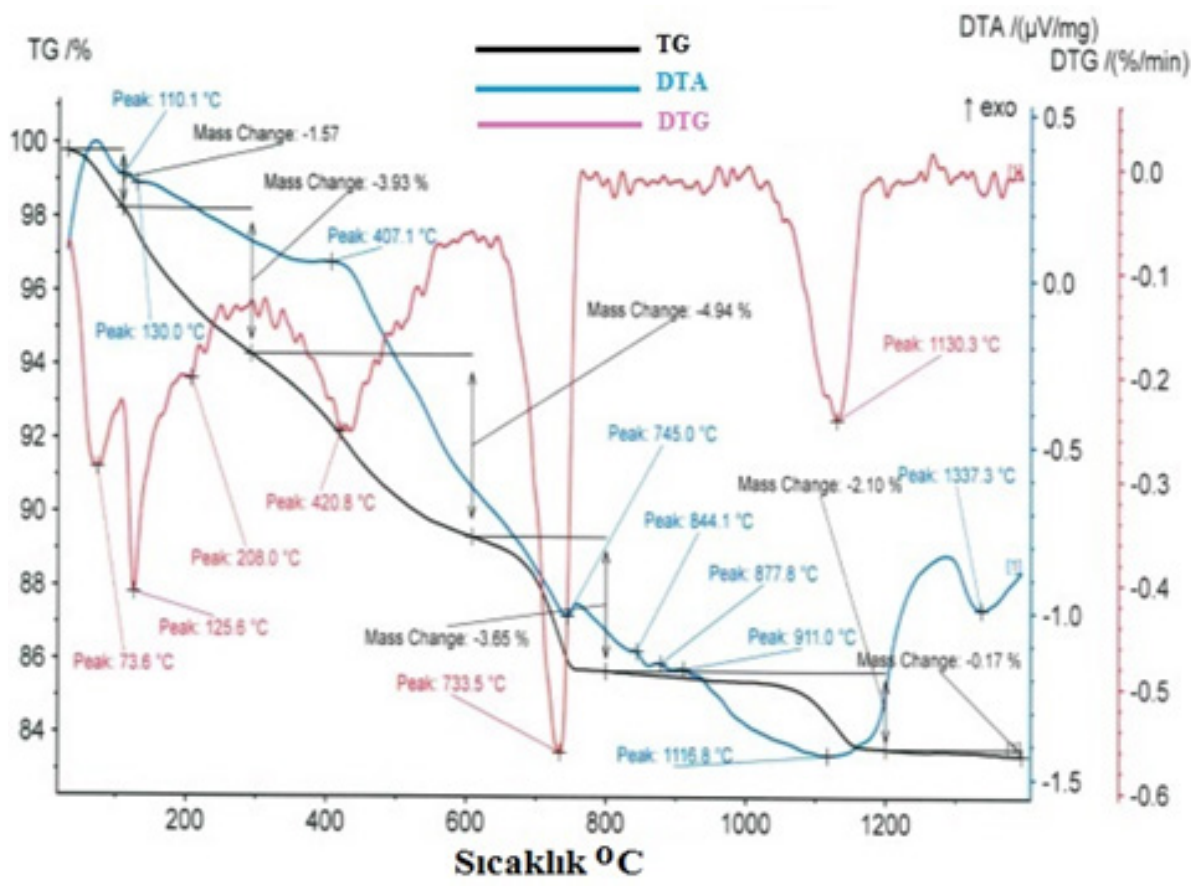

Şekil 7. Uçucu Küllere Ait TG/DTA Analizi

TG/DTA grafiğine bakıldığında sıcaklık artışı ile birlikte uçucu küllerin yapısında yaklaşık \% 18'lik bir ağırlık kaybının meydana geldiği görülmektedir. Bu değer küllerin kimyasal analiz sonucunda görülen ateş zayiatıyla hemen hemen aynıdır. Grafikte $730{ }^{\circ} \mathrm{C}$ 'de görülen keskin pik karbonat içeren fazların ya da kömürden gelen safsızııkların ayrışması olarak yorumlanabilir. Uçucu küllerin sıcak cam yüzeyinde kolay dağılmaması ve cam yüzeyine kolayca entegre olmamalarının nedeni küllerin Al2O3 ve $\mathrm{SiO} 2$ gibi oksitleri içeren yüksek sıcaklık fazlarını içeriyor olması olabilir (Goga vd. 2013: 338, Şensöğüt vd., 2002:146).

Uçucu küllerin sıcak cam üflemede kullanımlarında, kül/cam oranının artmasıyla cam tromelde ısıtıldığı zaman yüzeye uygulanana karışımın yüzeyle bütünleșmesi daha güç olmuştur. Daha çok topaklanma meydana gelmiştir ve cam yüzeyinde uçucu kül uygulanan bölgeler sertleştiği için camın şekillendirilmesi zorlaşmıştır. Cam üflenerek şişirildiğinde kaplamada çatlaklar meydana gelmiştir ve üflemenin şiddetine oranla bu çatlaklar daha da açııışır. Bu da yüzeyde artistik bir etki yaratmıştır ve altına alınan renk ile daha da belirgin hale getirilmiştir.
Şekil 8'de hazırlanan 4 farklı karışım (FA1, FA2, FA3, FA4-a, FA4-b) kullanılarak elde edilen cam objelere ait fotoğraflar görülmektedir.

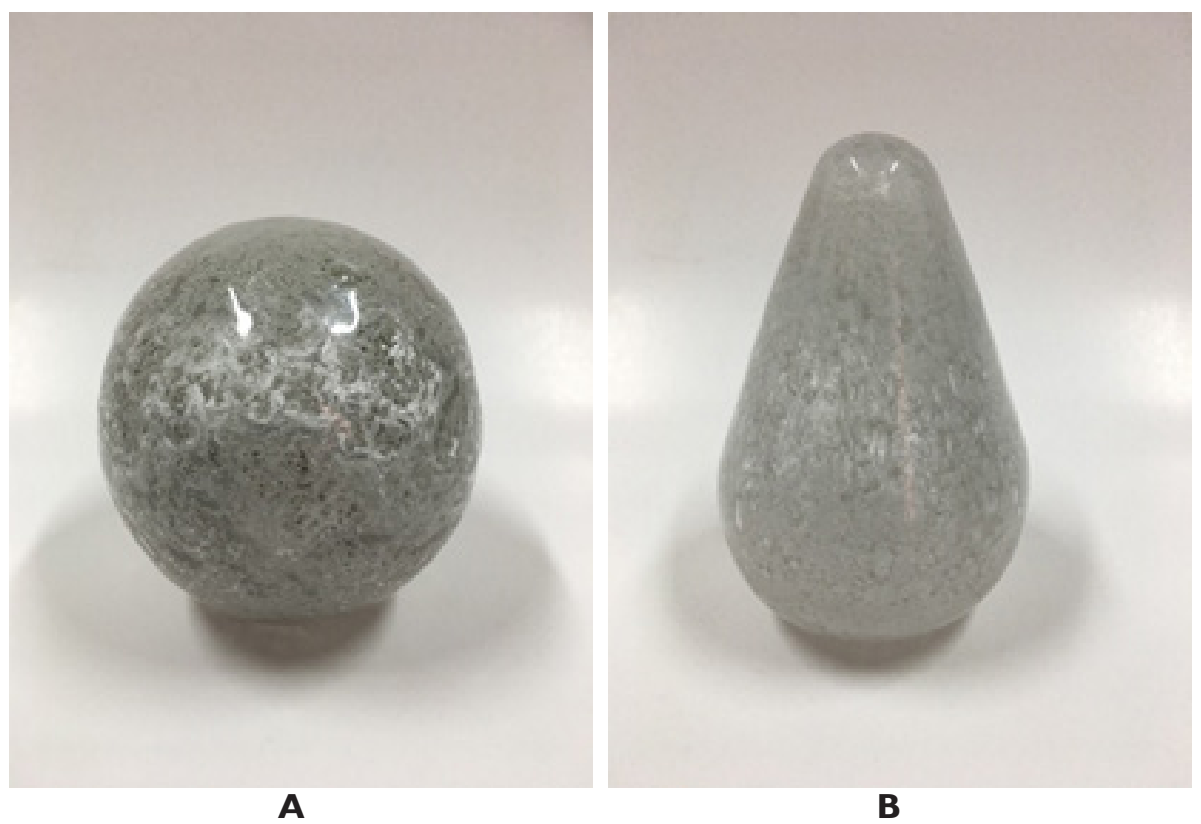

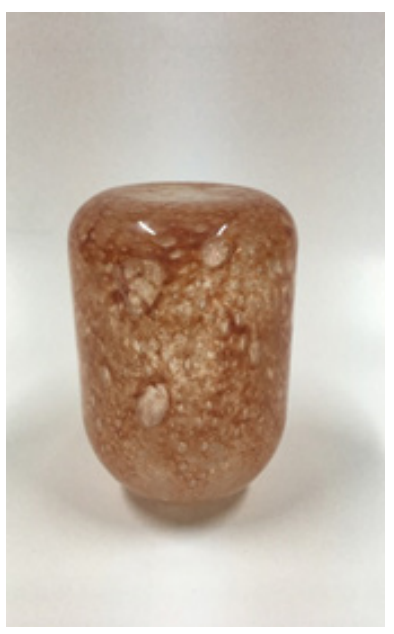

C

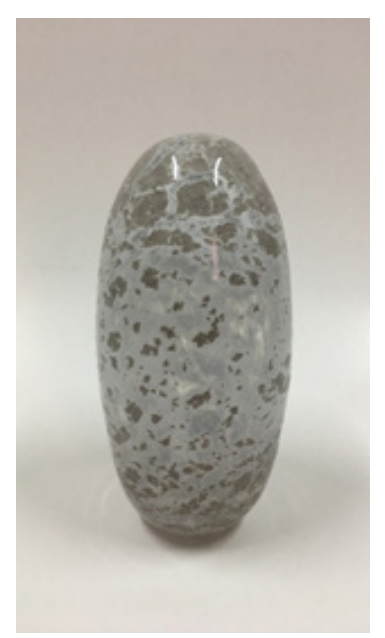

D

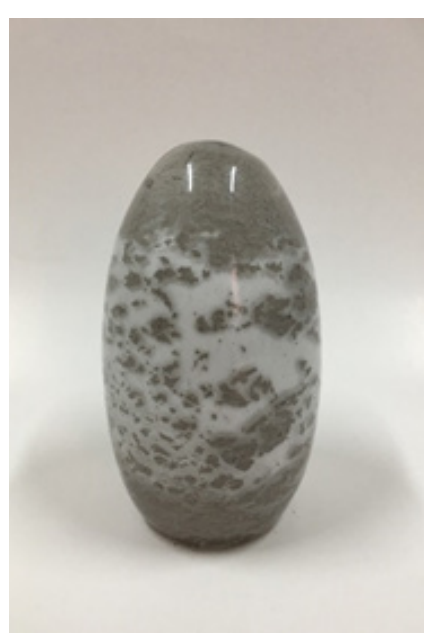

E
Şekil 8. (A) FAI $\quad$ (B) FA2 (C) FA3 (D) FA4-A Ve (E) FA4-B Kodlu Karışımlarla Yapılan Denemelere Ait Fotoğraflar 


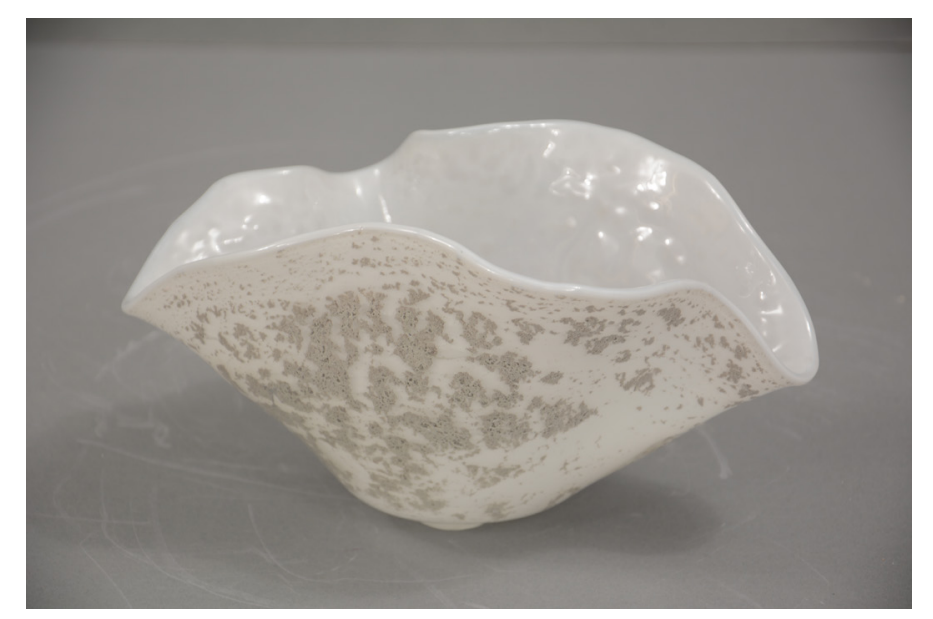

Şekil 9. FA4-B Kodlu Karışım Kullanılarak Üretilen Cam.

\section{Genel Sonuçlar}

Cam, birçok teknik ve ek malzeme kullanabileceğimiz çok yönlü bir malzemedir. Günümüze kadar birçok farklı biçimde kullanılagelmiştir. Dünyanın en eski ve çok yönlü, insan tarafından yaratılan malzemelerinden biridir.

Geri dönüşüm, depolama ve yakma intiyacını azaltır ve aynı zamanda kirliliğin azaltılmasına yardımcı olur. Uçucu kül kullanımı günümüzde artmıştır. Uçucu kül cam yüzeyinde farklı dekor etkisi elde etmek amacıyla sanatsal cam uygulamalarında yeniden kullanım için iyi bir adaydır. Sonuçlar cam dekorasyonunda uçucu küllerin kullanılması ile estetik ve orijinal etkilerin elde edilmesinin mümkün olduğunu göstermiştir 


\section{Kaynakça}

Amin, Sh. K., Sibak, H. A., El-Sherbiny, S.A. ve Abadir, M.F. (20I6). "An Overview of Ceramic Wastes Management in Construction", International Journal of Applied Engineering Research, ISSN 0973-4562, II (4), 2680-2685.

Beveridge, P., Doménech, I. and Miró, E. P. (2005). Warm Glass: A Complete Guide to Kiln-forming Techniques: Fusing, Slumping, Casting, Lark Books, 2005.

Capp, R. A. and Bush, R. G. (1984). Glass Etching: 46 Full-size Patterns with Complete Instructions, Courier Corporation.

Cummings, K. (2009). Contemporary Kiln-formed Glass: A World Survey, University of Pennsylvania Press.

Cornett, M. (2004). Easy Glass Etching, Sterling Publishing Company Inc

Goga, F. et al., "Fly ash from thermal power plant, raw material for glass-ceramic", Environmental Engineering and Management Journal, February 2013, Vol. I2, No. 2, 337342.

Junkes, J.A., Carvalho, M. A., Segadaes, A.M. and Hotzal, D. (201I). "Ceramic Tile Formulations from Industrial Waste, Interceram, 60 (I), 36-4I.

Littlea, M.R. (2008). "Production of novel ceramic materials from coal fly ash and metal finishing wastes", Resources, Conservation and Recycling, 52 (II), I329-I335.

Neal, M. (2002). Creative Glass Painting, F+W Media.

Norman, B. (20/2). Engraving and Decorating Glass: Methods and Techniques, Courier Corporation.

Openshaw, S. (1992). Utilization of Coal Fly Ash, Yüksek Lisans Tezi, Florida University, USA.

Petrie, K. (2006). Glass and Print, University of Pennsylvania Press.

Sear, L. K. A. (200I). Properties and Use of Coal Fly Ash: A Valuable Industrial By-product. Thomas Telford, 261 pages.

Sharma, G. (2003). "Possible Use Of Fly Ash In Ceramic Industries: An Innovative Method To Reduce Environmental Pollution", International Journal of Modern Physics: Conference Series, 22, 99-102.

Sinclaire, E. F. and Spillman, J. S. (1997). The Complete Cut \& Engraved Glass of Corning, Corning Museum of Glass, Syracuse University Press.
Sorvari, J. and Wahlström, M. (20/4). Handbook of Recycling", State-of-the-art for Practitioners, Analysts, and Scientists, Elsevier.

Şensöğüt, C. ve ark., "Bazi Yerli Kömürlerin Termogravimetrik Karakteristiklerine Istatistiksel Yaklaşim”, Türkiye 13 Komur Kontesi Bildiriler Kitabı, 29-3I Mayıs 2002, Zonguldak, Türkiye, s. I45-150.

Yeşilay, S. (2008). “Cam Dekorasyon Teknikleri”, Anadolu Üniversitesi Güzel Sanatlar Fakültesi Anadolu Sanat Dergisi, 19, I I I- I I6.

\section{Internet Kaynakları}

https://www.khanacademy.org/partnercontent/gettymuseum/antiquities/ ancientglassmaking/a/glassmaking-history-and-techniques 